\title{
Gas-phase interaction of protonated lysine with water
}

\author{
Marko Rožman, Dunja Srzić, Leo Klasinc
}

\begin{abstract}
Gas-phase interaction of $\mathrm{LysH}^{+}$with $\mathrm{D}_{2} \mathrm{O}$ has been investigated in order to elucidate the $\mathrm{H} / \mathrm{D}$ exchange reaction mechanism and possibility of water assisted ion-zwitterion structure formation. The proceed of the interaction is modeled by DFT calculations. Potential energy profiles for: the perturbation from ion-molecule to ion-zwitterion structure, the "flip-flop" and the "bridging" mechanism are presented. Analysis of H/D exchange kinetics results for $\mathrm{LysH}^{+}$with $\mathrm{D}_{2} \mathrm{O}$ and $\mathrm{CD}_{3} \mathrm{OD}$ measured in a Fourier transform ion cyclotron resonance (FTICR) mass spectrometer agree with ion-molecule structure of $\mathrm{LysH}^{+}$. Both experimental and theoretical findings suggest that during interaction of Lys $\mathrm{H}^{+}$with $\mathrm{D}_{2} \mathrm{O}$ isotopic exchange is favored over the water assisted conformational change from ion-molecule into ion-zwitterion structure.
\end{abstract}

\section{Introduction}

When the term "biomolecule" was first introduced as a name for molecules that were important in the living organism there was implicit connection to an aqueous milieu. The idea that such molecules might exist as gases was thought to be improbable. This view has changed slowly; indeed, it is now thought that many biomolecules might have originated in the gas-phase and that, later, they have become the building blocks of life in an aqueous environment. Thus, it is no surprise that one might search for the presence and production of biomolecules (e.g., amino acids) in interstellar clouds, comets, meteorites and micrometeorites [1-3], and that the comparison of gas versus solution structure and properties has become a hot scientific issue $[4,5]$.

Amino acids in aqueous media and over a wide range of $\mathrm{pH}$ exist in their zwitterionic ( $\mathrm{ZW}$ ) form. But, like many other biomolecules, they may change structure and properties upon transfer into the gas-phase. Both the extent and nature of change and in particular the number of water molecules which preserves the aqueous characteristics are important in chemistry, physiology and biology. Most neutral amino acids in the gas-phase exhibit a non-ionic molecular form (i.e., their amino group is not intramolecularly protonated). This was seen first in the photoelectron spectra of aliphatic amino acids [6-8] and confirmed later by photoelectron spectra correlation of the pairs (amino acid/amino acid methyl ester) versus (carboxylic acid/carboxylic acid methyl ester) [8]. Such a correlation would not exist if gaseous amino acids were ZW. A similar conclusion, namely a non-ionic structure of amino acids in the gas-phase was reached by correlating gas basicity with those of several reference bases $[9,10]$.

However, the ZW form can be stabilized in the gas-phase by appending an alkali metal cation. According to calculations on some cationized or neutral amino acids, both, the ZW and the molecular forms have nearly the same energy, and the stabilization of one or the other form and/or interconversion between them can be achieved by solvent [11-16], collision [17] and/or charge effects [18-22]. The number of water molecules and/or charge which determine a given structure $[11,12]$ is clearly of great interest. Indeed, in the field of hydrated gas-phase ions the search for the "Holy Grail" is to pinpoint the number of molecules needed to stabilize the $\mathrm{ZW}$ 
form of cationized amino acid. It was shown [23] theoretically that three water molecules caused the charge solvated (CS) and $\mathrm{ZW}$ forms of glycine to be degenerate. For cationized valine it was shown both experimentally and theoretically that three water molecules stabilize the $\mathrm{ZW}$ form [12,24]. It was also demonstrated [25] that the computed vibrational spectrum of a gas-phase alanine with four associated water molecules is very similar to that recorded in solution.

Currently stabilization of the cationized amino acid ZW form is treated mostly with successive addition of water molecules. New insights might be gained viewing at the problem "dynamically" by investigating the interacting partners and potential energy profiles of water assisted conformational changes. For example, an analysis of $\mathrm{AlaNa}^{+}$and its interactions with water, all aimed at elucidating the H/D exchange mechanism in sodiated amino acids, has shown that prior to H/D exchange a structure perturbation occurred from the CS into the $\mathrm{ZW}$ form [26]. In this perturbation, in which water acts as a catalyst one molecule of $\mathrm{H}_{2} \mathrm{O}$ suffices to produce the $\mathrm{ZW}$ form. This $\mathrm{ZW}$ form of amino acid is stable in the gas-phase because of the large barrier for ZW-CS conversion in the absence of water. The question now arises if the same is true for protonated amino acids. The best candidates for the $\mathrm{ZW}$ conformation of protonated amino acid are those with an extra amino group: $\operatorname{ArgH}^{+}$, $\mathrm{HisH}^{+}$and $\mathrm{LysH}^{+}$. The $\mathrm{H} / \mathrm{D}$ exchange in $\mathrm{ArgH}^{+}$with $\mathrm{CH}_{3} \mathrm{OD}$ and $\mathrm{ND}_{3}$ demonstrated reactivity at a single site [27]. It is speculated, because of the possibility that $\mathrm{NH}_{3}$ might attach a proton, that a ZW complex of Arg- $\mathrm{NH}_{4}{ }^{+}$is formed. For $\mathrm{HisH}^{+}$, the experimental results did not show existence of a $\mathrm{ZW}$ structure [28]. On the other hand results of $\mathrm{H} / \mathrm{D}$ exchange for $\mathrm{LysH}^{+}$indicate six equivalent hydrogens [29] and therefore a possibility of $\mathrm{ZW}$ structure formation. Although the six equivalent hydrogens could have been a consequence of the H/D exchange mechanism, it seemed worthwhile to investigate both experimentally and theoretically the possibility of $\mathrm{LysH}^{+}$perturbation into a $\mathrm{ZW}$ conformation. Consequently, we have simulated the perturbation mechanism that drives $\mathrm{LysH}^{+}$from its ion-molecule into its ion-ZW conformation and we have analyzed experimentally the $H / D$ exchange.

\section{Material and methods}

The H/D exchange experiments were performed in a $3 \mathrm{~T}$ Fourier transform ion cyclotron resonance (FTICR) mass spectrometer (Extrel FTMS 2001, Madison, USA). Lysine (Fluka, Buchs, Switzerland) MALDI samples were prepared with a standard dried-droplet procedure using 2,5-dihydroxybenzoic acid (DHB) as matrix. Protonated lysine ions were generated in the ICR cell with two consecutive $337 \mathrm{~nm}$ laser pulses from a nitrogen laser (VSL 337 NSD, LSI Laser Science, Newton, USA). After formation, all ions were allowed to cool for $1 \mathrm{~s}$ and then the monoisotopic $\mathrm{LysH}^{+}$ions were isolated with a SWIFT waveform. These ions were then allowed to react with a background pressure of a deuterium donor for various periods of time after which the resulting abundances of all present ions were determined from their mass spectra. Many such "snapshot" mass spectra yielded the time dependence of the exchange process, i.e., data for determination of site-specific rate constants (vide infra). The deuteration reagents were $\mathrm{D}_{2} \mathrm{O}(99.8 \%$, Aldrich, Milwaukee, USA) and $\mathrm{CD}_{3} \mathrm{OD}(99.8 \%$, Cambridge Isotope Laboratories, Andover, USA). The stabilized reagent gas pressure of $\sim 1.33 \times 10^{-5} \mathrm{~Pa}$ used in the exchange experiments was measured with a Bayard-Alper type ionization gauge using parameterized response factors for calibration [30]. All experiments were performed at an ambient temperature of $300 \mathrm{~K}$. During determination of the site-specific rate constants with our initial approach [31] (similar to those suggested in Ref. [32]) we encountered the problem of many minima appearing in fitting procedure, all with high errors in fit (LSS of fits was around 0.2). As best fit for the six exchanging sites it produced one group of three equivalent, another of two equivalent and one single exchange sites in ratios 6:2:1. The culprit for the encountered problem was increase of exchange sites resulting in exponential growth of corresponding differential equations. A similar situation was already observed for the protonated arginine dimer [27]. Therefore, we doubled the number of experiments and applied the "probability" treatment as suggested in Refs. [27,33]. The experimental curve fitting was done in Mathematica 4.0 (Wolfram Research, Champaign, USA). This treatment directly led to one minimum with a low error in fit (LSS from 0.1 to 0.04). It also worked much faster, consistent with Ref. [27]. The Fig. A.1 in Appendix A shows time dependence of normalized intensities of $\mathrm{LysH}^{+}$in a reaction with $\mathrm{D}_{2} \mathrm{O}$. Repetitive $\mathrm{H} / \mathrm{D}$ exchange experiments indicate a relative standard deviation of up to $20 \%$ for the reported site-specific rate constants. It is worth mentioning that the exchange rate ratios for the sites in each experiment remain unaffected by the number of experimental runs.

All calculations for various $\mathrm{LysH}^{+}$and $\mathrm{LysH}^{+}-\mathrm{D}_{2} \mathrm{O}$ conformers were performed using a B3LYP functional with 6-31G* basis set. In the calculations, the $\mathrm{D}_{2} \mathrm{O}$ molecule was mimicked by $\mathrm{H}_{2} \mathrm{O}$. The structures of the transition states were obtained by QST2 and QST3 optimization procedures. Stationary points (i.e., the minima on the potential energy surface (PES)) were tested by harmonic frequency analysis. Based on previous experience with similar systems [26] it was assumed that relative energies are independent of basis set superposition errors. All DFT calculations were performed using the GAUSSIAN 03 [34] program package.

\section{Results and discussion}

Lys, with its side chain amino group belongs to the group of basic amino acids. Because of its high proton affinity and its additional amino group, Lys is expected to be the preferred protonation site in peptides and proteins. The global PES minimum for $\mathrm{LysH}^{+}$is a conformation shown in Fig. 1; it contains a protonated side chain amino group, consistent with previous results [35]. The ion-molecule structure is stabilized by two intramolecular hydrogen bonds, both of which involve this protonated side chain amino group, one to oxygen of the acid carbonyl group and the other to the lone pair electrons of the $\alpha$-amino group, Fig. 1.

Deprotonation of the carboxylic group and simultaneous protonation of the $\alpha$-amino group produces the ion-ZW form which 


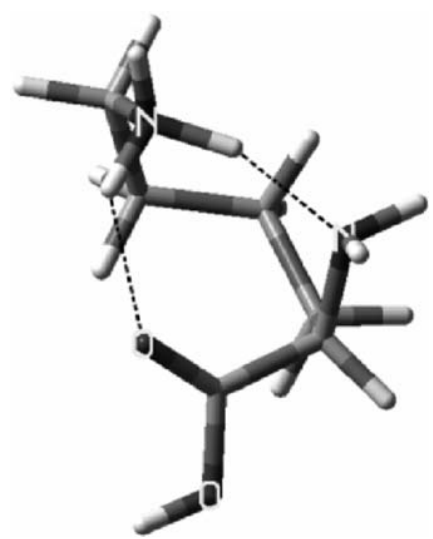

Fig. 1. B3LYP/6-31G* ion-molecule conformation of $\mathrm{LysH}^{+}$.

is $44.4 \mathrm{~kJ} \mathrm{~mol}^{-1}$ less stable than ion-molecule conformation of $\mathrm{LysH}^{+}$at the B3LYP/6-31G* level of theory. Addition of water diminishes this energy difference to $21.6 \mathrm{~kJ} \mathrm{~mol}^{-1}$ but the ion molecule form of $\mathrm{LysH}^{+}$remains the favored conformation. On the other hand (see Section 1), the interaction with water may change the conformation. Theoretical treatment of bimolecular interaction with water showed that within a few picoseconds, regardless of the collision site, water molecule is stabilized close to the charged and/or active sites [26,33]. Such active sites in $\mathrm{LysH}^{+}$are: the side chain protonated amino group, the $\alpha$-amino group and the carboxylic group (see Fig. 1). B3LYP/6-31G* optimized complexes with $\mathrm{D}_{2} \mathrm{O}$ at active sites of $\mathrm{LysH}^{+}$yielded the minimal energy conformations shown in Fig. 2. In NC complex water is stabilized by two hydrogen bonds between the protonated side chain amino group and the carbonyl oxygen while in $\mathbf{N 1}$ water is placed between the side chain protonated amino and the $\alpha$-amino group. $\mathbf{C 1}$ represents complex in which

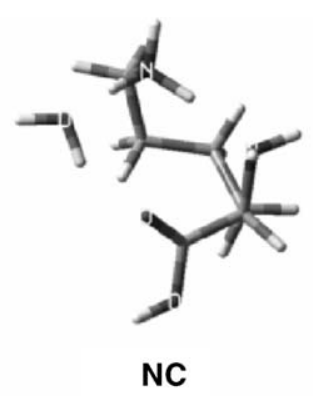

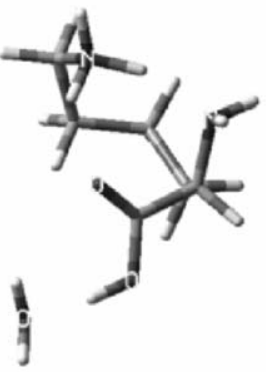

C1

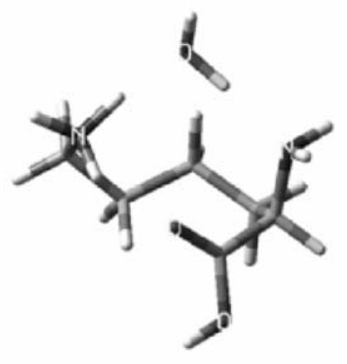

N1
Fig. 2. LysH $^{+}-\mathrm{D}_{2} \mathrm{O}$ complexes.

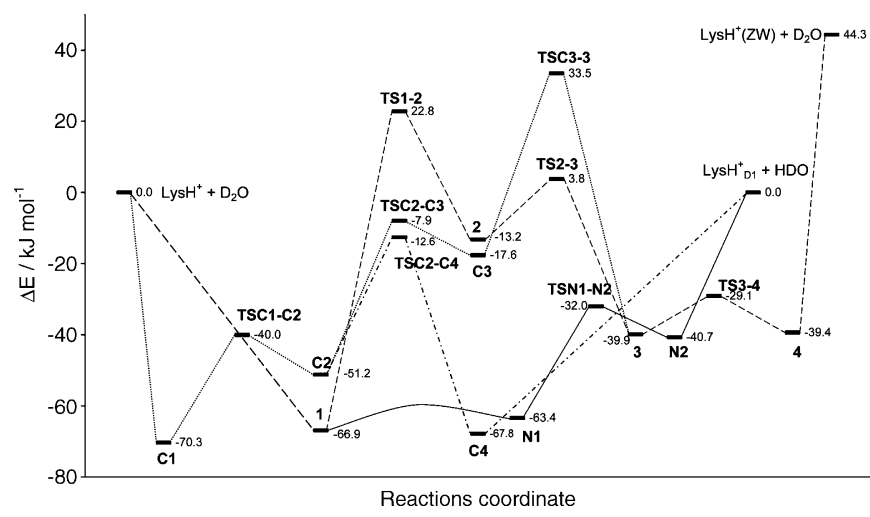

Fig. 3. Schematic representation of the potential energy profile of $\mathrm{LysH}^{+}-\mathrm{D}_{2} \mathrm{O}$ interaction at the B3LYP/6-31G* level of theory (together with Table A.1 in Appendix A).

water is stabilized by single hydrogen bond with carboxylic hydrogen.

$\mathrm{LysH}^{+}-\mathrm{D}_{2} \mathrm{O}$ complexes presumably represent the starting intermediates either in the $\mathrm{H} / \mathrm{D}$ exchange or in the perturbation reaction of $\mathrm{LysH}^{+}$during the whole of the $\mathrm{LysH}^{+}-\mathrm{D}_{2} \mathrm{O}$ interaction process. The potential energy profile for the $\mathrm{LysH}^{+}-\mathrm{D}_{2} \mathrm{O}$ interaction is shown in Fig. 3 and the optimized structures of the energy minima and transition states are depicted in Fig. 4. Absolute energies $(E)$ and relative stabilities $(\Delta)$ of computed structures are given in Appendix A.

\subsection{Perturbation of Lys $\mathrm{H}^{+}$}

Formation of an ion-ZW form of $\mathrm{LysH}^{+}$is a result of proton transfer from the carboxylic to the amino group. Two pathways for such a transfer exist in $\mathrm{LysH}^{+}$: (i) a first transfer from the protonated side chain amino group to the $\alpha$-amino group (amino $>\alpha$-amino) followed by another from the carboxylic group to the side chain amino group (carboxylic $>$ amino) or (ii) direct transfer from the carboxylic to the $\alpha$-amino group (carboxylic $>\alpha$-amino).

\subsubsection{Amino $>\alpha$-amino proton transfer}

This initial transfer is possible only in conformations NC and $\mathbf{C 1}$, Fig. 2. The modeling of the amino $>\alpha$-amino proton transfer in the NC conformation indicates that this transfer is improbable because during optimizations of the complex with a protonated $\alpha$-amino group proton returns to the side chain amino group. Although the initial amino- $\alpha$-amino transfer in the C1 conformation is viable, the next intergroup carboxylic-amino transfer is not possible: the water molecule near the carboxylic group impedes this transfer.

\subsubsection{Carboxylic $>\alpha$-amino proton transfer}

This perturbation mechanism is possible only if the $\mathrm{H}$-bonds of the starting complex breaks. Such break can be achieved through transition state $\mathbf{T S 1 - 2}$, which represents an $180^{\circ}$ rotational move of the $-\mathrm{OH}$ group from its position in minimum 1. A substantial move of the side chain in which the protonated amino group is solvated by the water, must also take place. After 


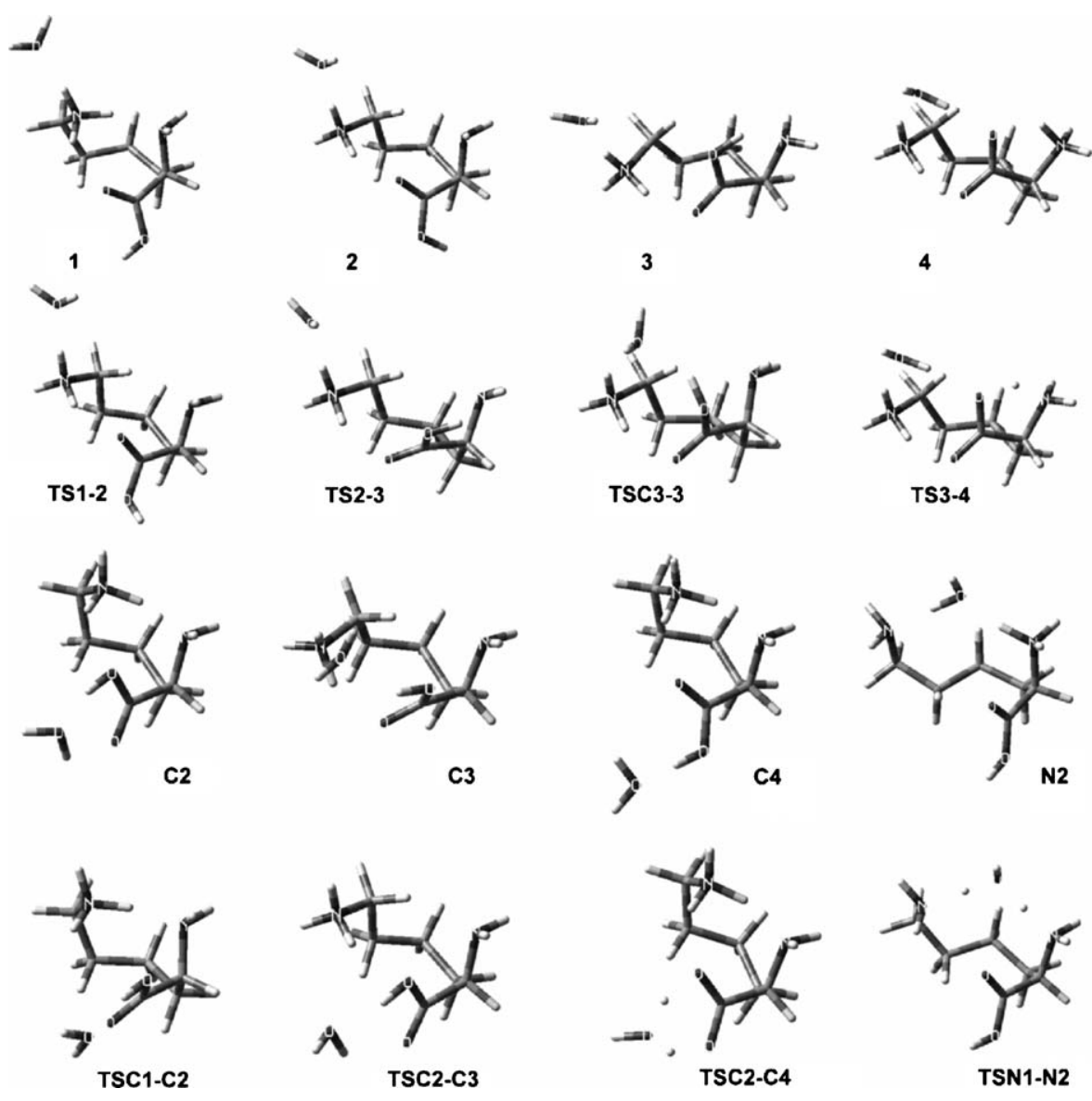

Fig. 4. $\mathrm{LysH}^{+}-\mathrm{D}_{2} \mathrm{O}$ interaction minima and transition states, results of B3LYP/6-31G* optimization.

formation of intermediate $\mathbf{2}$, the carboxylic group turns (TS2-3) and forms minimum 3 in which the proton transfer from the carboxylic to the $\alpha$-amino group takes place (TS3-4). Dissociation of final intermediate $\mathbf{4}$ produces the ion- $\mathrm{ZW}$ structure of $\mathrm{LysH}^{+}$. Another path to the $\mathrm{ZW}$ formation is also possible: an H-bond break can occur through TSC2-C3 by a rotation of the protonated amino group. The pathway to TSC2-C3 begins with the approach of a water molecule to the carboxylic group of $\mathrm{LysH}^{+}$ and the formation of minimum $\mathbf{C 1}$. The $\mathbf{C 1}$ then rearranges to C2 via $180^{\circ}$ rotation of the carboxylic group (TSC1-C2). Formation of intermediate $\mathbf{3}$ from minimum $\mathbf{C 3}$ has a large energy barrier (TSC3-3), $51.1 \mathrm{~kJ} \mathrm{~mol}^{-1}$, which is $33.5 \mathrm{~kJ} \mathrm{~mol}^{-1}$ higher than the energy gain from reactant complexation. However, the same complexation of reactants ( $\mathbf{1}$ and $\mathbf{C 1}$ ) may lead to a more accessible pathway (vide infra).

\subsection{H/D exchange mechanism}

The three $\mathrm{LysH}^{+}-\mathrm{D}_{2} \mathrm{O}$ complexes shown in Fig. 2 also represents starting intermediates of the H/D exchange reactions. The carboxylic hydrogen exchanges by a "flip-flop" mechanism [36,37] within complex C4. The complex NC supports the exchange on the protonated amino and carboxylic groups [37] while complex N1 contributes by a "bridging" mechanism [29] to exchange at the amino groups. Attempts to find transition state for initial interconversion between the $\mathbf{1}$ and
$\mathbf{N 1}$ in "bridging" mechanism failed. Because the minimum $\mathbf{1}$ resembles to the complex $\mathbf{N} \mathbf{1}$ and the energy difference between them is small one can assume that the water molecule actually oscillates around the side chain amino group. After or during dissociation of $\mathbf{N 2}, \mathrm{LysH}_{\mathrm{D} 1}{ }^{+}$returns (by a proton transfer, not shown in Fig. 3) to its most stable conformation, which results in needed product stabilization. Fig. 3 shows that both "flipflop" and "bridging" mechanisms will be in competition with the perturbation mechanism. From the potential energy profile of these reactions, it follows that in the $\mathrm{LysH}^{+}-\mathrm{D}_{2} \mathrm{O}$ interaction the $\mathrm{H} / \mathrm{D}$ exchange will be favored over the perturbation reaction. During the interaction, a combination of H/D exchange with perturbation may well occur and lead to even more complex reaction pathways. However, the two large energy barriers (TS2-3 and TSC3-3) which must be overcome to produce the ion- $\mathrm{ZW}$ form of $\mathrm{LysH}^{+}$suggest that this is not a very probable pathway.

\section{3. $H / D$ exchange}

In the H/D exchange experiments on $\mathrm{LysH}^{+}$, all six weakly bound hydrogens undergo exchange a result that is consistent with earlier reports $[29,38]$. The experimental data were treated as if they referred to six independently exchanging sites. The corresponding reaction rate constants for site-specific H/D exchange are shown in Table 1. 
Table 1

Site-specific $\left(k_{1}, k_{2}, \ldots\right) \mathrm{H} / \mathrm{D}$ exchange rate constants (in units of $10^{-11} \mathrm{~cm}^{3} \mathrm{~s}^{-1}$ molecules ${ }^{-1}$ ) for reaction of $\mathrm{LysH}^{+}$with $\mathrm{CD}_{3} \mathrm{OD}$ and $\mathrm{D}_{2} \mathrm{O}$

\begin{tabular}{lcc}
\hline & $\mathrm{CH}_{3} \mathrm{OD}$ & $\mathrm{D}_{2} \mathrm{O}$ \\
\hline$k_{1}$ & 26.7 & 9.5 \\
$k_{2}$ & 26.7 & 9.5 \\
$k_{3}$ & 26.7 & 9.5 \\
$k_{4}$ & 26.7 & 9.5 \\
$k_{5}$ & 26.7 & 9.5 \\
$k_{6}$ & 8.7 & 4.4 \\
\hline
\end{tabular}

Present rate constants indicate in protonated Lys five equivalent fast and one single slower exchanging sites. Both deuterated agents exhibit similar reactivity although $\mathrm{CD}_{3} \mathrm{OD}$ exchanges faster which is in agreement with previously observed behavior $[31,36,37]$. According to the presented potential energy profiles for H/D exchange five equivalent sites can be assigned to the amino groups while the single site can be attributed to the carboxylic group. An interesting effect here is increase of the amino groups exchange rates compared to those in aliphatic and aromatic amino acids where exchange at carboxylic sites is 10-100 times faster then for the amino site [31,32,36,37]. Similar increase was already observed in $\mathrm{HisH}^{+}$[28]. Observed effect is a consequence of at least two barrier free exchange processes (Fig. 3) while in H/D exchange of protonated aliphatic amino acids only carboxylic exchange is barrier free yielding a much faster exchange of carboxylic hydrogen [37].

A closer look at Fig. 3 may provide ideas for explanation of observed exchange sites distribution. Although Fig. 3 represents exchange and perturbation mechanisms in competition, "flip-flop" and "bridging" exchange mechanism are presented as transitions $\mathbf{C 4}>\mathbf{C 2}$ and $\mathbf{1}>\mathbf{N 1}>\mathbf{N} 2$, respectively. Theoretical treatment, i.e., potential energy profiles show that "bridging" mechanism is lower in energy but in both mechanisms reactant molecules possess enough energy for reaction and that reaction rates will be collisionaly controlled. Although the minimum energy paths have no barrier any movement away from the optimum geometry can increase the barrier height; in that case the

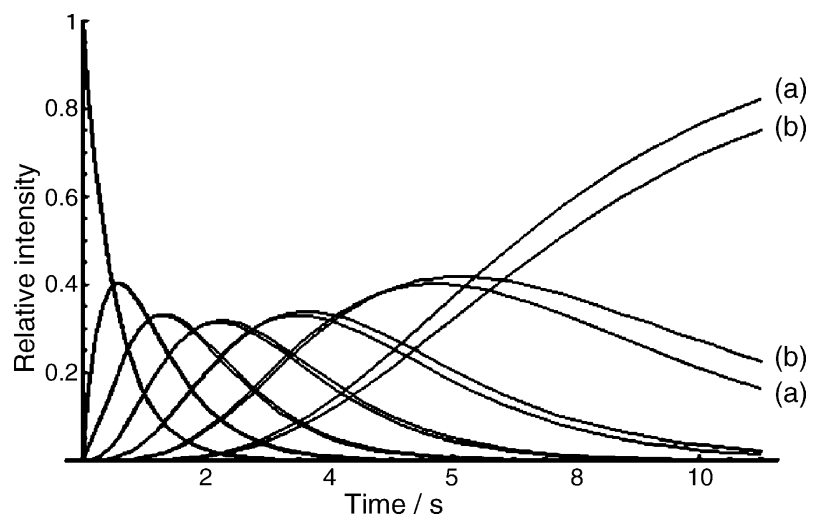

Fig. 5. Simulation of site-specific rate constants distribution in present $\mathrm{LysH}^{+}$ with $\mathrm{D}_{2} \mathrm{O}$ exchange experiment: (a) in case of six equivalent exchange sites and (b) for the $(5+1)$ site distribution according to Table 1 showing that differentiation between the two cases, if at all, is possible only towards end of reaction, i.e., where the experimental error is at maximum. steeper path (TSC2-C4) would be more sensitive to distortions than a flat one (TSN1-N2). On the other hand, bridging mechanism has a more compact transition state (TSN1-N2) which is consequently entropicaly unfavored.

Our result is in a way consistent with that reported for H/D exchange in protonated Lys by Green and Lebrilla [29] which showed presence of six equivalent exchangeable hydrogens. However, at least two barrier free processes which lead to the exchange of all six labile hydrogens may give their result. It remains, however, open whether our experiment and treatment is precise enough to reveal such fine differences (Fig. 5) or whether our result is just a consequence of a experimental error (e.g., decreasing signal with time).

\section{Conclusion}

In conclusion, combined experimental and theoretical results show that in the interaction between $\mathrm{LysH}^{+}$and water molecule in the gas-phase the possibility to create the ion-ZW form of $\mathrm{LysH}^{+}$is negligible. During this interaction the energetically much more favored isotope exchange will occur. It is demonstrated that a detailed study of the reaction mechanism enables correct interpretation of the H/D exchange experiment. The experimental results which indicate the existence of five equivalent and one slightly slower or roughly six equivalently H/D exchange sites of $\mathrm{LysH}^{+}$are in agreement with the theoretical interpretation of the experiment.

\section{Acknowledgements}

The authors acknowledge helpful discussions with Prof. S.P. McGlynn (LSU) while preparing this manuscript. The Ministry of Science, Education and Sports of Republic of Croatia and Croatian Academy of Sciences and Arts Foundation supported this work.

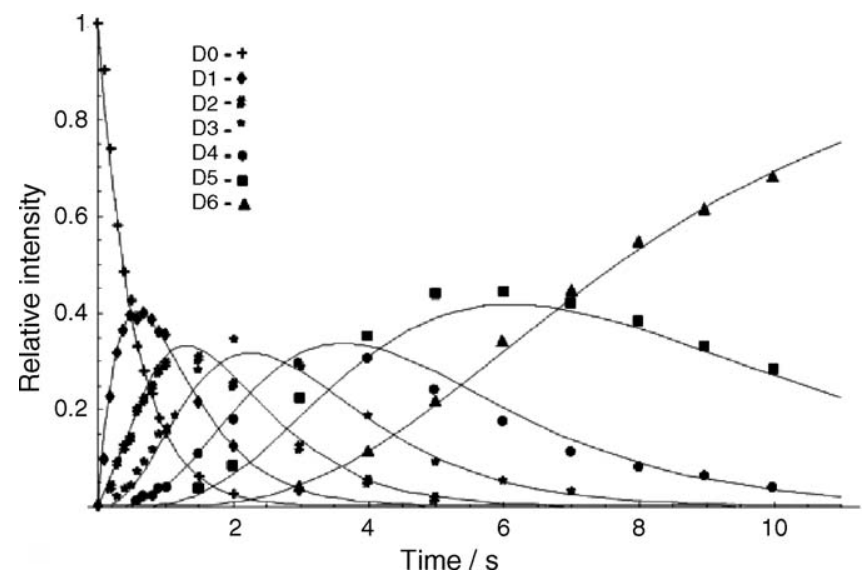

Fig. A.1. Time dependence of the experimental ion intensities and the corresponding theoretical fit obtained with the site-specific treatment in the H/D exchange reaction of the $\mathrm{LysH}^{+}$with $\mathrm{D}_{2} \mathrm{O}$. The least squares sum (LSS) for this fit amounted 0.037. $D_{n}$ represents an ion species containing a total of $n$ deuterium atoms. 
Table A.1

The B3LYP/6-31G* energies (in $E_{\mathrm{h}}$ ) and relative stabilities (in $\mathrm{kJ} \mathrm{mol}^{-1}$ ) of different structures in $\mathrm{LysH}^{+}-\mathrm{D}_{2} \mathrm{O}$ interaction

process

\begin{tabular}{llllr}
\hline Minimum & $E$ & \multicolumn{1}{c}{$\Delta$} & Transition state & \multicolumn{1}{c}{$\Delta$} \\
\hline LysH $^{+}+\mathrm{D}_{2} \mathrm{O}$ & -573.834974 & 0.0 & & \\
$\mathrm{LysH}^{+}(\mathrm{ZW})+\mathrm{D}_{2} \mathrm{O}$ & -573.853511 & 44.3 & TS1-2 & -573.826290 \\
$\mathbf{1}$ & -573.860442 & -66.9 & TS2-3 & -573.833524 \\
$\mathbf{2}$ & -573.840001 & -13.2 & TS3-4 & -573.846058 \\
$\mathbf{3}$ & -573.850156 & -39.3 & & -22.8 \\
$\mathbf{4}$ & -573.849973 & -39.4 & TSC1-C2 & -573.850226 \\
$\mathbf{C 1}$ & -573.861752 & -70.3 & TSC2-C3 & -573.838001 \\
$\mathbf{C 2}$ & -573.854482 & -51.2 & TSC3-3 & -573.822228 \\
$\mathbf{C 3}$ & -573.841693 & -17.6 & TSC2-C4 & -70.0 \\
$\mathbf{C 4}$ & -573.8608 & -67.8 & TSN1-N2 & -573.83977 \\
$\mathbf{N 1}$ & -573.859119 & -63.4 & & -573.847166 \\
$\mathbf{N 2}$ & -573.850473 & -40.7 & & -32.0 \\
\hline
\end{tabular}

\section{Appendix A}

See Fig. A.1 and Table A.1.

\section{References}

[1] A. Brack (Ed.), The Molecular Origins of Life, Cambridge University Press, UK, 1998.

[2] L.E. Snyder, Orig. Life Evol. Biosphere 27 (1997) 115.

[3] Y.J. Kuan, S.B. Charnley, H.C. Huang, W.L. Tseng, Z. Kisiel, Astrophys. J. 593 (2003) 848.

[4] P.E. Barran, N.C. Polfer, D.J. Campopiano, D.J. Clarke, P.R.R. Langridge-Smith, R.J. Langley, J.R.W. Govan, A. Maxwell, J.R. Dorin, R.P. Millar, M.T. Bowers, Int. J. Mass Spectrom. 240 (2005) 273.

[5] R. Weinkauf, J.P. Schermann, M.S. de Vries, K. Kleinermanns, Eur. Phys. J. D 20 (2002) 309.

[6] T.P. Debies, J.W. Rabalais, J. Electron Spectrosc. 3 (1974) 315.

[7] L. Klasinc, J. Electron Spectrosc. 8 (1976) 161.

[8] L. Klasinc, Int. J. Quantum. Chem. QBS5 (1978) 373.

[9] M.J. Locke, R.L. Hunter, R.T. McIver, J. Am. Chem. Soc. 101 (1979) 272.

[10] M.J. Locke, R.T. McIver, J. Am. Chem. Soc. 105 (1983) 4226.

[11] J.H. Jensen, M.S. Gordon, J. Am. Chem. Soc. 117 (1995) 8159.

[12] R.A. Jockusch, A.S. Lemoff, E.R. Williams, J. Phys. Chem. A 105 (2001) 10929.

[13] W. Wang, X.M. Pu, W.X. Zheng, N.-B. Wong, A.M. Tian, J. Mol. Struct. (Theochem.) 626 (2003) 127.

[14] S. Yamabe, N. Ono, N. Tsuchida, J. Phys. Chem. A 107 (2003) 7915.

[15] B. Balta, V. Aviyente, J. Comput. Chem. 25 (2004) 690.

[16] M. Rožman, Croat. Chem. Acta 78 (2005) 185.

[17] T.F. Miller, D.C. Clary, A.J.H.M. Meijer, J. Chem. Phys. 122 (2005) 244323.

[18] I.A. Topol, S.K. Burt, M. Toscano, N. Russo, J. Mol. Struct. (Theochem.) 430 (1998) 41.

[19] W.D. Price, R.A. Jockusch, E.R. Williams, J. Am. Chem. Soc. 120 (1998) 3474.

[20] R.A. Jockusch, W.D. Price, E.R. Williams, J. Phys. Chem. A 103 (1999) 9266.

[21] M. Noguera, L. Rodrigez-Santiago, M. Sodupe, J. Bertran, J. Mol. Struct. (Theochem.) 537 (2001) 307.
[22] A. Gapeev, R.C. Dunbar, Int. J. Mass Spectrom. Ion 228 (2003) 825.

[23] E. Kassab, J. Langlet, E. Evleth, Y. Akacem, J. Mol. Struct. (Theochem.) $531(2000) 267$.

[24] A.S. Lemoff, M.F. Bush, E.R. Williams, J. Am. Chem. Soc. 125 (2003) 13576.

[25] E. Tajkhorshid, K.J. Jalkanen, S. Suhai, J. Phys. Chem. B 102 (1998) 5899.

[26] M. Rožman, B. Bertoša, L. Klasinc, D. Srzić, J. Am. Soc. Mass Spectrom. 17 (2006) 29.

[27] O. Geller, C. Lifshitz, J. Phys. Chem. A 107 (2003) 5654.

[28] B. Kovčević, M. Rožman, L. Klasinc, D. Srzić, Z.B. Maksić, M. Yanez, J. Phys. Chem. A 109 (2005) 8329.

[29] M.K. Green, C.B. Lebrilla, Int. J. Mass Spectrom. Ion Proc. 175 (1998) 15.

[30] J.E. Bartmess, R.M. Georgiadis, Vacuum 33 (1983) 149.

[31] M. Rožman, S. Kazazić, L. Klasinc, D. Srzić, Rapid Commun. Mass Spectrom. 17 (2003) 2769.

[32] F. He, A.G. Marshall, J. Phys. Chem. A 104 (2000) 562.

[33] T. Wyttenbach, M.T. Bowers, J. Am. Soc. Mass Spectrom. 10 (1999) 9.

[34] M.J. Frisch, G.W. Trucks, H.B. Schlegel, G.E. Scuseria, M.A. Robb, J.R. Cheeseman, J.A. Montgomery Jr., T. Vreven, K.N. Kudin, J.C. Burant, J.M. Millam, S.S. Iyengar, J. Tomasi, V. Barone, B. Mennucci, M. Cossi, G. Scalmani, N. Rega, G.A. Petersson, H. Nakatsuji, M. Hada, M. Ehara, K. Toyota, R. Fukuda, J. Hasegawa, M. Ishida, T. Nakajima, Y. Honda, O. Kitao, H. Nakai, M. Klene, X. Li, J.E. Knox, H.P. Hratchian, J.B. Cross, C. Adamo, J. Jaramillo, R. Gomperts, R.E. Stratmann, O. Yazyev, A.J. Austin, R. Cammi, C. Pomelli, J.W. Ochterski, P.Y. Ayala, K. Morokuma, G.A. Voth, P. Salvador, J.J. Dannenberg, V.G. Zakrzewski, S. Dapprich, A.D. Daniels, M.C. Strain, O. Farkas, D.K. Malick, A.D. Rabuck, K. Raghavachari, J.B. Foresman, J.V. Ortiz, Q. Cui, A.G. Baboul, S. Clifford, J. Cioslowski, B.B. Stefanov, G. Liu, A. Liashenko, P. Piskorz, I. Komaromi, R.L. Martin, D.J. Fox, T. Keith, M.A. Al-Laham, C.Y. Peng, A. Nanayakkara, M. Challacombe, P.M.W. Gill, B. Johnson, W. Chen, M.W. Wong, C. Gonzalez, J.A. Pople, Gaussian 03, Revision B.05, Gaussian Inc., Pittsburgh, PA, 2003.

[35] A.A. Bliznyuk, H.F. Schaefer III, I.J. Amster, J. Am. Chem. Soc. 115 (1993) 5149

[36] S. Campbell, M.T. Rodgers, E.M. Marzluff, J.L. Beauchamp, J. Am. Chem. Soc. 117 (1995) 12840.

[37] M. Rožman, J. Am. Soc. Mass Spectrom. 16 (2005) 1846.

[38] N.N. Dookeran, A.G. Harrison, J. Mass Spectrom. 30 (1995) 666. 